\title{
Providing claimants with access to information: A comparative analysis of the POPIA, PAIA and HPCSA guidelines
}

\author{
M van Niekerk, MSc (Med) (Bioethics and Health Law), BOccTher; Dip Voc Rehab, BProc \\ Department of Occupational Therapy, School of Therapeutic Sciences, Faculty of Health Sciences, University of the Witwatersrand, Johannesburg, \\ South Africa
}

Corresponding author: M van Niekerk (matty.vanniekerk@wits.ac.za)

\begin{abstract}
South African healthcare practitioners who compile reports on claimants on behalf of others, for example insurers, often face a dilemma when claimants request access to their reports. A search of the literature revealed limited guidance for such healthcare practitioners that accurately reflects practice issues, and takes cognisance of the Promotion to Access to Information and Protection of Personal Information Acts (PAIA and POPIA). Since private practices are exempt from producing PAIA manuals, practitioners are not expected to be familiar with access to information processes beyond the Health Professions Council of South Africa (HPCSA) guidelines. Based on a comparative analysis of the POPIA, PAIA and HPCSA guidelines, this article makes recommendations to practitioners and the HPCSA. Practitioners who have onceoff engagements with claimants (without a prior therapeutic relationship) to establish claimants' eligibility for contractual benefits should refer claimants' access requests to the instructing party. As a statutory regulator, the HPCSA should align its guidelines with other legislation and incorporate the provisions of POPIA and PAIA to better guide and protect practitioners.
\end{abstract}

S Afr J Bioethics Law 2019;12(1):32-37. DOI:10.7196/SAJBL.2019.v12i1.656

Practitioners who provide information to third parties about patients and/or claimants often face a dilemma when these patients/claimants request access to this information: how should the healthcare practitioner go about disclosing information to the patient/claimant when a third party has an interest in that information?

In South Africa (SA), when consumers claim benefits from institutions such as the Road Accident Fund (RAF), pension funds or insurance companies, healthcare practitioners are often called upon to provide medical information to substantiate the claims. Practitioners provide medical information either in their capacity as a treating practitioner or as an independent healthcare practitioner. In the role of independent healthcare practitioner, there is typically a once-off interaction with the claimant in a distinct context, wherein the claimant exercises a right in relation to a contract between the claimant and another party, or in terms of legislation such as the Road Accident Fund Act No. 56 of 1996.

While the Health Professions Council of SA (HPCSA) guidelines on disclosing clinical information to patients are straightforward, ${ }^{[1,2]}$ there is a lack of clear procedural guidance to practitioners in instances where another party has an interest in the disclosure. This may be due to insufficient integration of principles from the Promotion of Access to Information Act No. 2 of $2000^{[3]}$ (PAIA) into the HPCSA guidelines, despite their 2016 review. Furthermore, healthcare practitioners in private practice have been exempted from producing PAIA manuals, ${ }^{[4]}$ and there is therefore no expectation that practitioners providing information to third parties such as the RAF or insurers will have such manuals. The PAIA is not part of the usual medical regulatory sphere of HPCSA-registered health practitioners and is not routinely included in undergraduate training, and therefore health practitioners may not be familiar with its provisions.

This article aims to clarify for SA healthcare practitioners the process of providing claimants with access to information. This will be achieved by explaining the nature of the contract between an insurer and a claimant, and its relation to the healthcare practitioner as either an independent contractor or a treating practitioner. The explanation will make clear the gaps in the HPCSA guidelines with respect to the process of providing access to information to patients and claimants themselves, especially for independent practitioners who gather information on behalf of a third party such as an insurer. In order to clarify the process of providing access to information, a comparative analysis of the HPCSA guidelines, ${ }^{[1,2]}$ the Protection of Personal Information Act No. 4 of 2013 (POPIA) ${ }^{[5]}$ and the PAIA, will be made. These results, in addition to relevant literature and case law, will be presented by first describing the nature of the relationships between the role players. Thereafter, the distinction between a patient and a claimant, and the role of the healthcare practitioner in relation to each, will be explained, using an analysis of the POPIA. Lastly, the HPCSA guidelines and the PAIA will be compared, to explain accessto-information procedures.

This article does not focus on obtaining a patient's consent for disclosing information to third parties; the HPCSA guidelines, ${ }^{[1,2]}$ as well as the POPIA and the National Health Act No. 61 of 2003 (NHA), ${ }^{[6]}$ require consumers to provide informed consent for disclosure of their medical information to others. Instead, it focuses on those instances where a consumer requests access to their own medical information that is held by persons who are not their treating practitioners. 
For present purposes, it is assumed that at the time of entering into a contract such as an insurance contract, the consumer understood its provisions and therefore made an informed decision to enter into it.

\section{The need for medical information arises from a contract}

Consumers engage in multiple contracts over their lifetime. Some may be relatively informal and assumed, but others may be reduced to writing, such as a formal signed contract between a consumer and an insurer.

In the usual therapeutic situation, the healthcare practitioner and the patient are the primary parties to the treatment agreement (or contract) between them. This relationship is governed by the $\mathrm{NHA}^{\left[{ }^{[6,7]} \mathrm{A}\right.}$ patient's consent must always be obtained before disclosing information to others ${ }^{[2,6,8,9]}$ because of the underlying norms of patient autonomy ${ }^{[10]}$ and confidentiality, ${ }^{[1,2]}$ and this is legally required by the NHA. This relationship is independent from any other contracts in which the consumer may engage (Fig. 1).

The relationship between the consumer and the insurer is governed by the contract, which creates duties and rights for both parties, as demonstrated by Fig. 1. Once the consumer and the insurer have entered into the contract, the consumer has duties, for example, to pay their monthly premiums. The insurer has a duty to pay any claim arising from the contract, which is suspended pending occurrence of the insured event. When the insured event occurs, the consumer's right to claim may be suspended pending provision of medical information. In these contracts, the primary parties are the claimant and the insurer. The healthcare practitioner is a third party who, based on his or her medical expertise, must provide information to the insurer to determine, either from existing records or from a special once-off assessment, whether the claimant's insured benefits have become claimable or not. Therefore, the insurer may request information from a treating healthcare practitioner or an independent practitioner, but neither healthcare practitioner is party to the contract between the insurer and the consumer. While there is a prior relationship between the treating healthcare practitioner and the consumer, the independent healthcare practitioner does not stand in

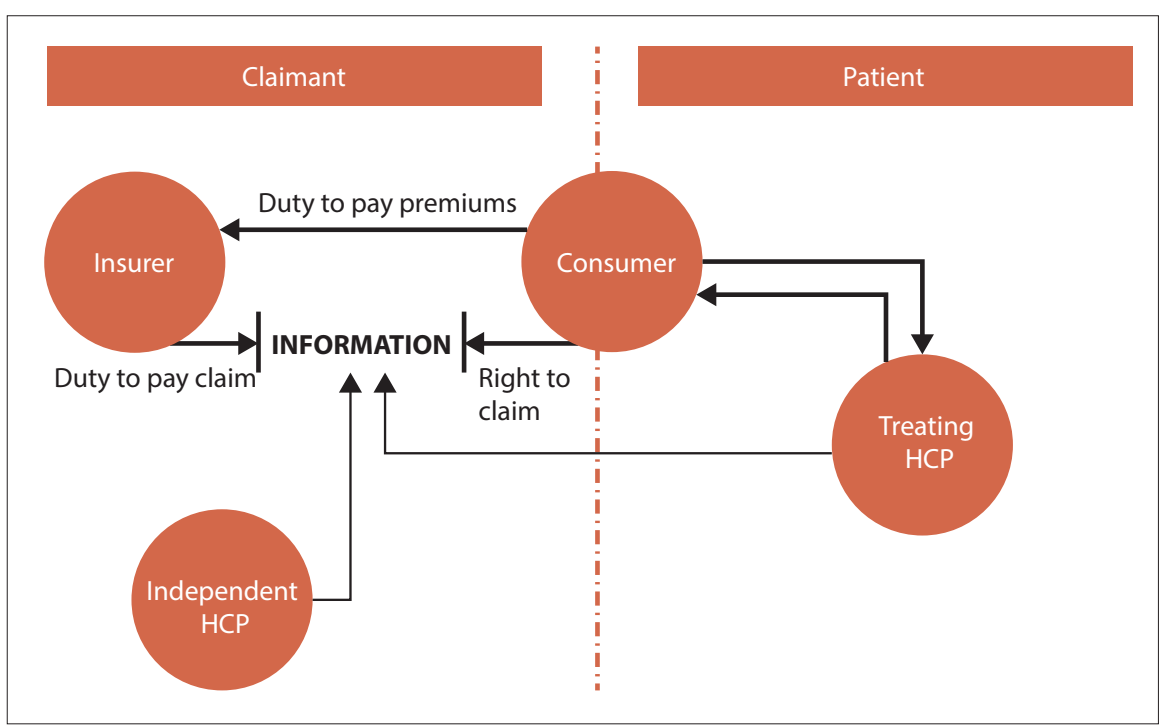

Fig. 1. Contractual relationship between consumer and insurer. $(H C P=$ healthcare provider. $)$

any contractual or prior relationship with the consumer. For the purpose of this article, therefore, a distinction is made between a claimant, who consults with a healthcare practitioner for the sole purpose of generating information to be disclosed to another party, and a patient, who has a prior clinical or therapeutic relationship with a practitioner (Fig. 1).

\section{A claimant is not a patient}

The purpose of a once-off interaction between the claimant and the independent healthcare practitioner is to generate and disclose specific information about the claimant to the other contractual party (i.e. the insurer) to meet contractual terms. This is different from the patient's interaction with their regular healthcare practitioner, in which a trusting, caring, therapeutic relationship is established, aimed at rendering healthcare services. A patient does not engage with their regular healthcare practitioner with the purpose of generating specific information to be disclosed to others - rather, there is a duty on a practitioner to keep the patient's information confidential, and not disclose it without expressed consent. ${ }^{[9,10]}$

The NHA does not make specific provision for situations of intersectoral collaboration, such as in the case of insurance assessments. Since, in these instances, a healthcare practitioner's aim is not to render healthcare services, but to use their expertise to provide an expert opinion to assist the insurer in establishing whether a claimant meets the contractual provisions, the NHA does not provide guidance and assistance to healthcare practitioners in this specific context. Because the purpose of the once-off interaction with an independent contractor differs from the ordinary therapeutic relationship, it cannot be envisaged that a usual patient-physician relationship will be established with an independent healthcare practitioner, or that such a relationship could reasonably be anticipated. Therefore, where the insurer refers the claimant to a relevant independent healthcare practitioner solely in relation to the provisions of the contract between the claimant and insurer, any duties ${ }^{[1,11]}$ healthcare practitioners have towards the claimant arise from this contract between the claimant and the insurer, and not purely from the interaction between the healthcare practitioner and the claimant (Fig. 1). While the claimant may reasonably have expectations regarding professionalism from an independent healthcare practitioner, and the practitioner is not exempt from ensuring informed consent for gathering and disclosing information, ${ }^{[1,2,5,8-10]}$ it is unlikely that a claimant would expect identical fidelity from the independent healthcare practitioner as from his or her own treating practitioner.

Unlike the NHA, the HPCSA guidelines (in booklet 5) do address contexts where healthcare practitioners act in non-clinical roles, ${ }^{[2]}$ particularly in relation to obtaining consent to disclose a patient's information to another party. Guideline 8 deals with disclosing information for purposes other than treatment, such as insurance and work purposes, and guideline 9.2 deals with disclosures where practitioners have 
dual loyalties, e.g. when providing information either from existing records, or from specific evaluations for insurance purposes. ${ }^{[2]}$ In contrast with Fig. 1 above, the guidelines do not seem to adequately distinguish between situations where the practitioner has a preexisting relationship with the consumer, and those where the healthcare practitioner has to provide an independent opinion on the consumer. Interestingly, both guidelines 8 and 9.2 could apply to both situations, where the consumer is either a patient or a claimant, thus appearing to conflate the roles of healthcare practitioners in relation to patients and claimants. Importantly, the HPCSA does not distinguish between these roles with respect to providing consumers with access to their information at all, thus not taking cognisance of the nature of the contract between the consumer and another party, such as an insurer.

Although the NHA and HPCSA do not provide clear guidance to practitioners in contexts such as the consumer claiming insured benefits, the POPIA sheds more light. It describes two roles of persons who gather information about a consumer: that of the responsible party, and that of the operator. ${ }^{[5]}$

Section 18 of the POPIA ${ }^{[5]}$ requires someone who gathers information about a consumer to inform that consumer who the responsible party is. Therefore, where an independent healthcare practitioner gathers information about a claimant, it is his or her duty to inform the claimant of the identity of the responsible party. Section 1 of the POPIA ${ }^{[5]}$ defines the responsible party as any person, or public or private body, who determines what happens to information from a procedural and processing perspective. Where independent healthcare practitioners gather data about a claimant in order to enable the insurer to execute the provisions of the original contract (Fig. 1), the independent practitioner does not have decision-making powers regarding the information in relation to the insurance/contractual purpose of the gathered information. The independent healthcare practitioner is thus merely a proxy, or a source of information, for the insurer. Because it is the insurer and not the healthcare practitioner who is the decision-maker, determining what happens to the information and how it is used in terms of the contract between the claimant and the insurer, the insurer is the responsible party. It follows, then, that the independent healthcare practitioner must inform the claimant that the insurer is the responsible party (because of the contract between the claimant and the insurer).

In this instance, the independent healthcare practitioner is considered an operator, in terms of section 1 of the POPIA: ${ }^{[5]}$ someone who gathers information for a responsible party in terms of a contract or mandate, while not falling under their direct authority. To the contrary, however, where the insurer obtains information from a treating healthcare practitioner, the treating practitioner remains the responsible party for his or her clinical records. The POPIA thus further underscores the different relationship between an independent and a treating healthcare practitioner in relation to the consumer (as a claimant and patient, respectively).

The case of an independent healthcare practitioner generating specific information about a claimant for the sole purpose of disclosure to another (acting as an operator, in terms of the POPIA) must therefore be distinguished from that of a treating practitioner providing information to a third party about their existing patient (who remains the responsible party in terms of the POPIA). This distinction is particularly necessary in order to provide adequate guidance to independent contractors who are healthcare practitioners, both in terms of gathering and disclosing information to an insurer, and in the case where claimants request access to their information from an operator, or independent healthcare practitioner.

\section{Claimants accessing their information}

While patients have the right to access their information, ${ }^{[1,2,6,9]}$ independent healthcare practitioners acting as operators in terms of the POPIA to gather information about claimants often face a conundrum regarding claimants' requests for access to their information. The addition of another party with an interest in the information (who is the responsible party with decision-making power regarding the information) brings about uncertainty regarding the process to follow to address such a request for access. As has been indicated, the NHA does not provide specifically for this context, nor do the HPCSA guidelines, which are closely aligned to the Act. Therefore the PAIA, ${ }^{\left[{ }^{[3]}\right.}$ which was promulgated specifically to provide for access to information, will be analysed for guidance regarding providing access to such information.

In addition to the two roles the POPIA ${ }^{[5]}$ describes in relation to information, namely that of responsible party and operator, the PAIA $^{[3]}$ distinguishes a third role - that of the party who controls the record. Importantly, in terms of section 4 of the $\mathrm{PAIA}_{1}^{[3]}$ it is usually the responsible party who controls a record ${ }^{[3]}$ which in this case is the insurer. Therefore, where a healthcare practitioner generates a record following a once-off assessment of a claimant, the record is deemed to belong to the insurer in terms of section 4 of the PAIA, ${ }^{[3,12]}$ read with section 1 of the POPIA. ${ }^{[5]}$ This is an important distinction, as the PAIA provides that access should be requested from the person who owns or controls the record, i.e. the responsible party. ${ }^{[3,12]} \mathrm{A}$ responsible party could be a private body, e.g. an insurer, or a public body, e.g. the RAF.

The PAIA prescribes different routes for accessing information from public and private bodies. Table 1 shows that public bodies' information officers have additional functions regarding the process of providing access to information, among others of which is to transfer a misdirected request for access to an appropriate public body. ${ }^{[13,14]}$

Where a request for access to information is made to a public body and another public body also holds that information, a decision needs to be made as to whether it would better serve that other public body's and the requester's interests to transfer the request to it. Currie and Klaaren ${ }^{[13]}$ explain that often, multiple public bodies have similar information about a person, and members of the public are not necessarily certain about who holds information about them. Furthermore, they argue that it is not reasonable to expect the public to know each of the myriad institutions and departments that comprise the public sector, nor to expect a public body to obtain information that they do not possess or control. Importantly, a public body may not refuse a request because they do not have or control the information, hence this duty on the information officer of a public body to transfer a request. This does not, however, hold for private bodies, who may refuse a request on these grounds. ${ }^{[13]}$

The information officer of a public body must transfer a request for access to information when:

- the request has erroneously been made to the public body and they neither have, nor control, the requested information; or 
Table 1. Summary of procedure for dealing with access-to-information requests ${ }^{[13]}$

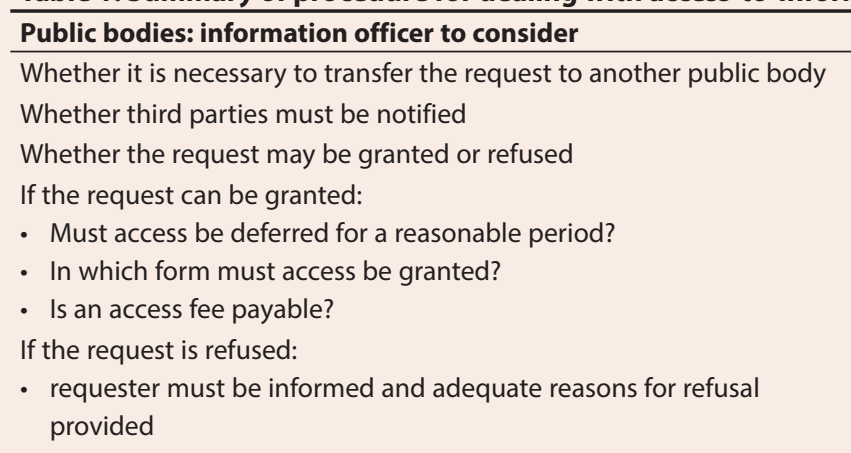

- they possess or control the information, but another public body has a greater interest in the record than the recipient. ${ }^{[3,13]}$

In the case of the second instance, where another public body has a greater interest in the information, it is argued that both the requester's and the public body's needs would be 'better served by ensuring that the personnel most familiar with the information will process the request'.[13] Transferring the request does not automatically ensure access: together with transferring the request, the duty to decide on granting or refusing access ${ }^{[13]}$ is transferred.

The PAIA does not place a corresponding duty to transfer a request on private bodies, arguably because private bodies cannot be expected to be familiar with the activities of other public or private bodies. ${ }^{[12,13]}$ However, where practitioners acting as independent contractors generate information and records for another body, e.g. insurers, the situation more closely resembles that of multiple public bodies holding records about a person.

Independent contractors do know for whom they have created a record, and therefore transferring a request is simple. The instructing body is likely to have a greater interest in the information than the independent contractor, because it contributes to the insurer's decision about the original contract. Furthermore, if practitioners have informed the claimant of the name and address of the responsible party right at the outset when gathering information, ${ }^{[5]}$ claimants will not be surprised when the request for access is transferred.

Reading sections 4,19 and 20 of the PAIA ${ }^{[3]}$ together, it can be argued that:

- another body, i.e. the instructing body (e.g. insurer) has a greater interest in the record than the independent healthcare practitioner who received the claimant's request for access; and

- the healthcare practitioner knows who the other body is, owing to his or her relationship as independent contractor to this body; and

- the needs of the requester (claimant) and the insurer will be better met by allowing personnel most familiar with the information to handle the request.

Therefore it seems reasonable to expect a healthcare practitioner who is acting as an independent contractor to transfer a request for access to information to the instructing body. In accordance with sections 19 and 20 of PAIA, such a transfer must be done within 14 days of receipt of the original request. ${ }^{[3,13]}$

\section{Private bodies: head of body to conside}

Whether third parties must be notified

Whether the request may be granted or refused

If the request can be granted:

- In which form must access be granted?

- Is an access fee payable?

If the request is refused:

- requester must be informed and adequate reasons for refusal provided

\section{Discussion}

There are distinct differences in the relationship between a claimant and an independent healthcare practitioner, and a patient and his or her regular treating practitioner. Because the purposes of engagement with healthcare practitioners in these roles are different, the expectations from patients and claimants should not be identical. The HPCSA, however, draws an unclear distinction between the roles of independent and treating practitioners, and their respective relationships to claimants and patients. This results in unclear guidance to both practitioners and the public, particularly in the context in which independent healthcare practitioners are called upon to provide information about a claimant arising from a contract between the claimant and another party such as an insurer. This is likely to create an incorrect expectation in the public that healthcare practitioners must grant them absolute access to their information, including in situations where the healthcare practitioner is not the responsible party. By not adequately acknowledging those instances where another entity is the responsible party, the HPCSA places an unjust responsibility on the independent healthcare practitioner to make decisions about granting claimants access to their information. In this regard, the HPCSA guidelines are not aligned to the POPIA ${ }^{[5]}$ and PAIA. ${ }^{[3]}$ As a result, practitioners are often in a quandary when dealing with claimants' requests to access their own information. The POPIA $^{[5]}$ and PAIA ${ }^{[3]}$ provide much clearer guidance to practitioners, by clearly distinguishing roles. When practitioners understand the distinction between a responsible party and an operator ${ }^{[5]}$ and the consumer is informed accordingly, decision-making around access requests becomes much clearer and easier, as illustrated by Fig. 2 .

When public bodies' ability to transfer requests for access to information in terms of the PAIA ${ }^{[3]}$ is considered, it becomes possible to provide clear procedural guidance to independent healthcare practitioners as to what should be done with claimants' requests for access to their own information. Because the insurer is the responsible party and has a greater interest in the information, independent healthcare practitioners should transfer requests to the insurer within 14 days of receipt ${ }^{[3,13]}$ (Fig. 2). It is important to note that the independent practitioner should not tell the requester to address their request to the insurer, which would constitute refusal of access, but that the independent practitioner should send the request to the information officer of the insurer within 14 days of receipt. ${ }^{[3,13]}$ It would be prudent for the practitioner to inform the claimant of the transfer. Since the independent healthcare practitioner should have 


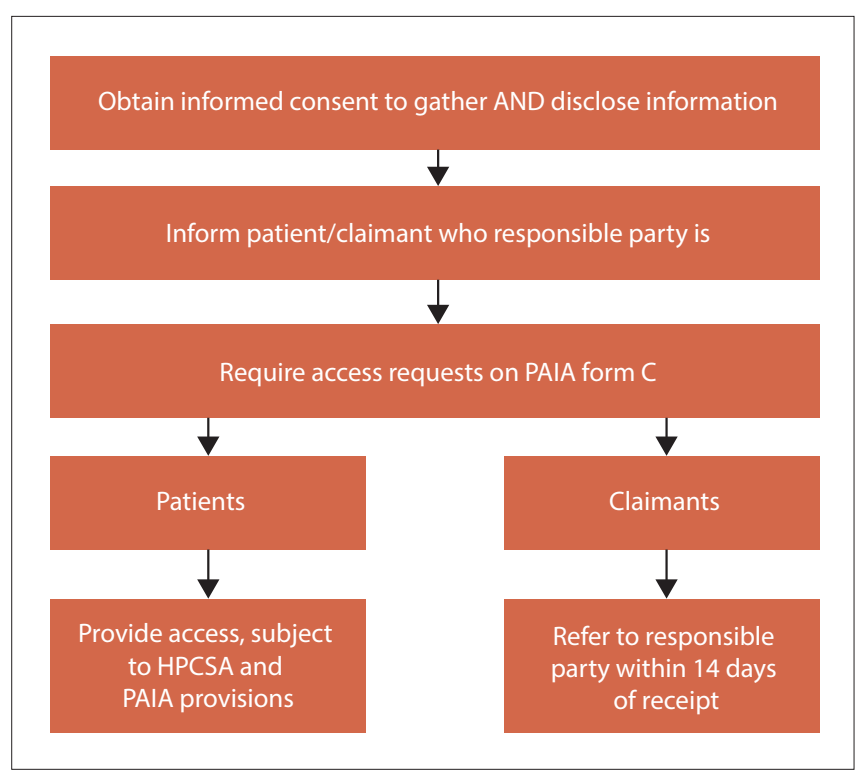

Fig. 2. Processing access-to-information requests. (PAIA = Promotion of Access to Information Act No. 2 of 2000; HPCSA = Health Professions Council of South Africa.)

informed the claimant at the outset that the insurer is the responsible party in accordance with section 18 of the POPIA, ${ }^{[5]}$ such a transfer should not be anticipated to catch the claimant unawares.

Therefore when gathering information on behalf of a responsible party, or providing information to another party from existing records, practitioners should obtain informed consent, which means that they should always inform consumers who the responsible party is in terms of the consumer's information. Consumers should know the purpose of gathering the information, and whether disclosing the information to another party is compulsory or voluntary. ${ }^{[5]}$

The PAIA requires both public and private bodies to publish a PAIA manual, which explains the procedures consumer should follow to access information. A number of private bodies, including private healthcare practices, have been exempt from this requirement, ${ }_{1}^{[4]}$ but nonetheless, private practices still receive access to information requests. The processing of requests for access to information would be improved if private practices had a policy or procedure detailing how patients and claimants (or others) should request access to information. This should include the manner in which access should be requested, as well as who should deal with such requests and what fees are payable. The PAIA prescribes fees for accessing information, as well as a form that a requester must complete. Transferring a request will be much easier if requests are made on the prescribed PAIA form - form $C$, in the case of private bodies. ${ }^{[3,13]}$ Requiring access requests to comply with the norms of the PAIA will further enhance the ability of an insurer (who is not exempt from producing a PAIA manual) to process the request. Because of the sensitive nature of access-to-information requests, it is preferable that these are dealt with by the practice owner, rather than delegated to another employee. Therefore, it is in private healthcare practices' and practitioners' own interests to compile a PAIA manual, particularly those that regularly gather information about claimants on behalf of other parties such as insurers.

\section{Conclusion}

Healthcare practitioners are increasingly called upon to step out of their usual clinical role to evaluate and report on claimants for nonclinical purposes, such as eligibility for insured benefits. As a result, practitioners no longer only relate to consumers as patients, but also as claimants. This article has drawn a distinction between the roles of the healthcare practitioner, and the respective expectations of patients and claimants. Conflating these roles, expectations and relationships results in inadequate guidance to healthcare practitioners, particularly in the context of independent healthcare practitioners gathering information about a claimant arising from a contract between the claimant and another party, i.e. acting as an operator in terms of the POPIA. ${ }^{[5]}$

Since the HPCSA guidelines do not adequately guide practitioners acting as operators, this article argues that the principles of the POPIA ${ }^{[5]}$ and PAIA, ${ }^{[3]}$ read together, be applied to cases where claimants request access to their information from operators (i.e. independent healthcare practitioners), and has described the rules that healthcare practitioners should apply. It is argued that the dynamics between the healthcare practitioner, insurer and claimant resemble the position wherein multiple public bodies hold information about a person; therefore the author proposes that practitioners adopt the procedure applicable to public bodies, to transfer a request for access to the relevant responsible party within 14 days of application..$^{[3,13]}$

From a practice perspective, this article provides guidance to practitioners who conduct evaluations and compile reports for medicolegal, insurance or pension fund benefits, when processing claimants' requests for access to their information. The guidance is based on a comparative analysis of HPCSA guidelines ${ }^{[1,2]}$ and the POPIA ${ }^{[5]}$ and PAIA. ${ }^{[5]}$ Future amendments of HPCSA guidelines should incorporate principles from these Acts, as the establishment of the Information Regulator brings the country closer to full implementation of the POPIA. ${ }^{[5]}$ Healthcare practitioners, irrespective of the roles they fulfil, will also be subject to the authority of the Information Regulator, and therefore the HPCSA should protect its members by providing clearer guidelines for ethical disclosure of information.

Acknowledgements. The author wishes to acknowledge the anonymous reviewers' thought-provoking comments which enhanced the clarity and flow of the paper.

Author contributions. Sole author.

Funding. None.

Conflicts of interest. MvN is the chairperson of the Professional Board for Occupational Therapy, Medical Orthotics and Prosthetics, and Arts Therapy of the HPCSA, and the chairperson of the Health Committee of the HPCSA.

1. Health Professions Council of South Africa. Booklet 1: General ethical guidelines for the healthcare professions. Pretoria: HPCSA, 2016. http://www.hpcsa.co.za/ Uploads/editor/UserFiles/downloads/conduct_ethics/Booklet 1.pdf (accessed 15 September 2017).

2. Health Professions Council of South Africa. Booklet 5: Confidentiality: Protecting and providing information. Pretoria: HPCSA, 2016. http://www.hpcsa.co.za/ Uploads/editor/UserFiles/downloads/conduct_ethics/Booklet 5.pdf (accessed 15 September 2017) 
3. South Africa. Promotion of Access to Information Act No. 2 of 2000.

4. South Africa. Promotion of Access to Information Act No. 2 of 2000. Regulations: Exemption of certain private bodies to complete manual. Government Gazette No 39504, 2015 (published under Government Notice No. 1222).

5. South Africa. Protection of Personal Information Act No. 4 of 2013

6. South Africa. National Health Act No. 61 of 2003.

7. Carstens $P$, Pearmain D. The regulatory framework of the South African health system. Med Law 2009;28:91-124. https://heinonline.org/HOL/Page?handle=hein journals/mlv28\&id=103\&div=10\&collection=journals (accessed 10 July 2018).

8. Health Professions Council of South Africa. Booklet 4: Seeking patients' informed consent: The ethical considerations. Pretoria: HPCSA, 2016. http://www.hpcsa co.za/Uploads/editor/UserFiles/downloads/conduct_ethics/Booklet 4.pdf (accessed 15 September 2017).

9. Oosthuizen $\mathrm{H}$, Verschoor T. Ethical principles becoming statutory requirements. S Afr Fam Pract 2008;50(5):36-40. https://doi.org/10.1080/20786204.2008.10873757
10. Dhai A. Informed consent - 2008. S Afr J Bioethics Law 2008;1 (1):27-30. http://www. sajbl.org.za/index.php/sajbl/article/view/5/9 (accessed 9 July 2018).

11. Dhai A, McQuoid-Mason DJ. Bioethics, Human Rights and Health Law: Principles and Practice. Cape Town: Juta \& Company Ltd, 2011.

12. O'Connor T. PAIA unpacked: A resource for lawyers and paralegals. Braamfontein Freedom of Information Programme: South African History Archive, 2013. http://foip. saha.org.za/uploads/images/PAIA UNPACKED.pdf (accessed 12 September 2017).

13. Currie I, Klaaren J. The Promotion of Access to Information Act commentary Claremont: Siber Ink, 2002

14. Claase v Information Officer of South African Airways [2006] SCA 163 (RSA). 